\title{
Teknoloji Bağımlılığının Semptomlar Temelinde İncelenmesi
}

Mert KÜçÜKVARDAR, MÜ, illetişim Fakültesi Bilişim Doktor Adayı, elektronik posta: mertkvardar @gmail.com

Özhan TINGÖY, Prof. Dr., MÜ, iletişim Fakültesi Öğretim Üyesi, Gazetecilik Bölüm Başkanı elektronik posta: otingoy@marmara.edu.tr

ÖZ

Teknoloji bağımlıllı̆̆ üzerine kesin bir uzlaşı olmamasına ră̆men yapılan çalışmalarda başlangıçta belirli bir amaç için kullanilan teknolojilerin git gide hayatın kendisi olmaya başladığı vurgulanmaktadır. Teknoloji bağımlılığı, normal bağımlılıklar gibi dış kimyasal uyarncılar içermese de yapılan çalışmalarda insanların duygu (limbik) sistemlerini etkilemesi bakımından iç kimyevi bir yapı içerdiğgi ortaya konulmuştur. Araştırmalara göre, kullanıcılar teknolojik araçları kullanımı sırasında belirli bir miktar mutluluk (dopamin) hormonu salgilamaktadır. Her yeni kullanımda kullanicılar daha fazla mutlu olmak adına teknolojiyle daha fazla vakit geçirme isteği duymaktadır. Teknoloji bağımlılı̆̆ üzerindeki belirleme kıstasları ise oldukça çeşitlidir. Tıbbi olmayan bu durum özellikle aktif (video oyuncusu) ya da pasif (TV izleyicisi) olarak görülebilir. Ancak temelinde teknolojik bağımlılık bir davranışsal bağımlılık olarak açıklanabilir.

Haziran 2018'de Dünya Sağllk Örgütü (WHO), Uluslararası Hastalıkların Sinıflandırılmasını (ICD-11) yaptığı tanı kılavuzunun 11'nci sürümünde "Bilgisayar Oyun Bă̆ımlılığı" çalışmalarının "Ruhsal Sağlık Problemleri" başlı̆̆ı altına aldığını açıkladı ve dünya genelinde sağlık sorunlarının teşhis edildiği bu kllavuzda oyun bağımlılığı resmen tanındı. Kriterler, teknoloji kullanım sıklı̆̆l, yoğunluğu, süresi, öncelik stralaması ve olumsuz durumlara rağmen kullanıma devam edilmesi gibi durumlar üzerine odaklanmaktadır. Bu semptomlarn destekleyici olarak son yıllarda teknoloji kullanımının insan zihni ve bedenine etkileri üzerine çok sayıda araştırma yapıldı. Aşırı teknoloji kullanımının artan stres, uyku bozuklukları ve klinik depresyon semptomların tetikleyebildiği sonucuna varıldı. Ayn zamanda teknolojiyle bütünleşik sanal ortamda birç̧ok dijital hastalı belirtisi ortaya çıktı. Bunların başında, kaçırma korkusu (FOMO), nomofobi (nomophobia), tekno-stres (technostress) gibi birçok kavram gündelik yaşama girdi ve popüler araştırmalarm konusu haline geldi.

Teknoloji bağımlılığı çalışmaları incelendiğinde konuyla ilgili sınırlılıklar ve tartışmalardan bahsetmek mümkündür. Konunun disiplinlerarası olması bu tartışmaları beraberinde getirmektedir. İlk ciddi problem teknoloji bağımlılı̆̆ın alt alanları olan bilgisayar, akıllı telefon, sosyal medya, oyun bağımlılı̆̆ gibi başlıkların teknoloji bağımlılığı çatısı altında birleştirilmemesidir. Yani bir başka ifadeyle konuyla ilgili yapılan ilk çalışmalar alt alanların açıklanması süreciyle başlamıştır. Ayrıca incelenen çalışmalardaki ortak nokta teknoloji bağımlılık konusunun nedensellik boyutundaki durumları açıklama yetersizliğidir. Teknoloji kullanım, bireyde daha önceden var olan problemleri tetikliyor mu yoksa daha önceden var olmayan problemler mi ortaya çıarıyor gibi sorular üzerindeki tartışmalar sürmektedir.

Bu araştırmada literatür taraması yapılmıştır. Mevcut olan teknolojik bağımlılık konusuna ait olgular, araştırma, tartışma ve öneriler derlenerek ortaya konulmuştur. 


\section{Investigation of Technology Addiction Based on Symptoms}

ABSTRACT There is no precise definition of technology addiction. However, it is emphasized in the studies that the technologies used for a specific purpose are becoming increasingly life itself. Technology addiction does not include external chemical stimulants such as normal dependencies, but studies have shown that technology addiction affect people emotion (limbic) systems because of internal chemical structure. According to research, users release a certain amount of happiness (dopamine) hormone during the use of technological tools. In every new use, users are willing to spend more time with technology to be more happy. The criteria for determining technology addiction are quite diverse. Technology addiction can be seen as particularly active (video player) or passive (TV monitor). However, on the basis of technological addiction can be explained as a behavioral addiction.

World Health Organization (WHO), announced the new diagnostic guide which is The International Classification of Diseases (ICD-11). The diagnostic guide explains that computer game addiction is a mental ilness. According to the guide, game addiction was officially recognized. Criteria focus on the frequency of technology use, intensity, duration, priority, and continued use despite adverse situations. In recent years, a lot of research has been done on the effects of technology use on human mind and body. It has been concluded that the use of excessive technology may present with symptoms of increased stress, sleep disorders and clinical depression. At the same time, the technology-integrated virtual environment has shown many signs of digital disease. Many concepts such as fear of missing out (FOMO), nomophobia, techno-stress have become a subject of daily life and popular research.

When the technology addiction studies are examined, it is possible to talk about some related limitations and discussions. The interdisciplinary nature of technology addiction brings about these debates. The first serious problem is that computers, smart phones, social media, gaming addiction are not unification under the roof of technology addiction. In addition, when the studies are examined, it is seen that the common point of the technology addiction issue is insufficient to explain the causality dimension. Discussions on questions such as the use of technology are triggering problems that have already existed in the individual or revealing problems that did not exist before.

A literature review was conducted in this study. The subjects related to technology addiction were gathered by collecting research, discussion and suggestions.

Keywords: Technology addiction, technology addiction symptoms, digital disease

\section{GíRiş}

Bilişim çağı, tüm dünyanın parmak ucunda olduğu hem iyi hem de kötü yönleri içeren aynı zamanda teknolojiyle bütünleşmesinden hareketle birey, toplum, kültür ve çok daha farklı sayıda alana etki eden bir anlayışı temsil eder. Bilişim çağının önemi onunla ne yapılabileceğinin farkına varıldığı durumlarda ortaya çıkar. Bu çağın en etkin araçları teknolojik tabanlıdır. Bu nedenle son on yılda teknoloji kullanımının insan zihni ve beden üzerindeki etkileri üzerine çok fazla araştırma yapıldı. Araştırmalar genel olarak incelendiğinde aşırı teknoloji kullanan kullanıcıların artan stres, uyku bozuklukları ve klinik 
depresyon semptomlarıyla karşılaşabileceği ön görülmektedir. Bu semptomlar özellikle genç erişkinlerde daha da baskındır. Çünkü genç erişkinler yapısı gereği teknolojiye ve araçlarına yüksek düzeyde maruz kalmaya elverişlidir. Üstelik bu maruz kalma fiziksel ve zihinsel etkileri beraberinde getirmektedir. Dolayısıyla teknoloji bağımlılığı üzerine yürütülen araştırmalar öncelikli olarak bu etkileri ön plana çıkarmayı amaçlamaktadır. Teknolojilerin hayatı üretken hale getiren bir fenomen olması ilerleyen dönemlerde yapılacak olan çalışmalarla konunun çok daha farklı boyutlarla çözümlenebileceğini işaret etmektedir.

Modern dünyada yapay ihtiyaçların ortaya çıkarılması ve insanlığın bu ihtiyaçlara önlemez bir biçimde özlem duymasıyla dünya oldukça farklı bir değişim gösterdi. İhtiyaçların sürekli yenilenmesi nedeniyle insanoğlunun özlemi hiçbir zaman sona ermedi. Teknoloji ve teknolojik araçlar bahsi geçen özlemin en önemli figüranlarını oluşturdu. İnsanların göz boyayıcı nesnelere gerçekten ihtiyacının olup olmadığını bilmeden yönelmesi modern bağımlılık olgusunun farklı bir yönünü temsil ediyor. Gereksiz ihtiyaçların insanlar için olmazsa olmaz bir düzleme taşınması günümüz pazarlama anlayışının bir sonucudur. Buradaki en önemli nokta bilim ve teknolojinin insanlara egemen olması anlayışının yerini insanın bilim ve teknolojiye egemen olduğu bir anlayışa bırakması gerektiğidir. Böylesi bir egemenlik ise insanlığın tüketimin tutsaklığından kurtarıldığ 1 ve öz değerlerin ön planda olduğu yapılanmayla çözülebilir.

Günümüzde sosyo-ekonomik statünün sembolleri haline gelen teknolojik araçlar kuşaklara yayıldı. X, Y, Z kuşaklarını temsil eden bireylerin sahip olduğu teknolojik olanların çeşitli olması teknoloji bağımlılığına yönelik araştırmaların farklı kıstaslar altında incelenmesine yol açmaktadır. Teknolojiye yönelik ilginin beraberinde ciddi sonuçlar getirdiği görülmektedir. Bahsi geçen etkilerin gündelik hayata en belirgin yansıması, ebeveynlerin sıklıkla oğullarının veya kızlarının giderek cep telefonlarına bağımlı oldukları belirtmesi, video oyunları oynamaları ya da televizyon izlemeleri gibi konulardaki şikâyetlerinde görülebilir. Artık insanlar teknolojik araçların birer kölesine haline gelmişçesine davranışlar sergilemektedir. Hafta sonlarını ya da boş vakitlerinin büyük bir bölümünü cihazlar önünde tüketmeyi tercih eden insanlar eski değerlerden hızla uzaklaşmaktadır. Çocuklar ise oyun konsolları önünde video oyunları oynamanın dışında sosyal ağlarda yüksek düzeyde aktiflik göstermektedir. Yetişkinlerin teknolojik araçları yoğun kullanması onları kimi zaman daha tembel ya da pasif hale getirebiliyor zira çocuklarda çoğu zaman video oyunlardaki oyunlar nedeniyle sinirli hale gelebiliyor.

Artık teknolojinin geniş bir şekilde toplumu devraldığını görüyoruz. İnsanların teknoloji konusunda hemfikir olduğu temel konu; teknolojinin kesinlikle günden güne geliştiği ve insan yaşamı için gittikçe daha önemli hale geldiğidir. Kuşaklar arasında teknoloji kullanımı farklılaştıkça ebeveynler, eğiticimler, araştırmacılar bu konu üzerine daha çok ağırlık vermeye başladı. Bugünkü genç yetişkinleri anlamaya yönelik acil bir ihtiyaç söz konusu. Genç bireyler artık arkadaşlarıyla birlikte daha az zaman geçiriyor, sosyal medya ve mesajlaşma etkinliklerini sanal ortamlar üzerinden sürdürüyor. Bu durum belki de daha önce görülmemiş düzeyde kaygı, depresyon ya da yalnızlık durumlarını ortaya çıkarıyor. İnsanların harcadıkları zamanın, gösterdikleri davranışların, ibadet biçimlerinin, olaylara karşı tutumlarının teknoloji tabanlı farklılaşması söz konusu. Tamamen farklı yollarla 
sosyalleşmeyi tercih eden, bir zamanlar kutsal olan sosyal tabuları ret eden, hayatlarını değişik bir biçimde sürdürmeyi amaçlayan bir topluluk ortaya çıktı.

Teknolojinin bazı alışkanları körelttiği açık. Bundan yüzyıllar önce Platon, "Phaidros" isimli eserinde mısır kültürün ait yazı teknolojisi konusunda Sokrates'le aralarında geçen diyaloga vurgu yapar ve özetle Sokrates'in, yazı teknolojisinin insanların hafızalarına dayanan anıların silinmesi tetikleyeceği ve insanları unutkan hale getireceği hususunda kaygılı olduğunu belirtmiştir (Platon, 2014). Sokrates'in o zamanlarda tahmin ettiği şekliyle bugün insanlar, teknolojilerin insani ilişkileri ikinci plana attığ1 konusunda endişeliler. Bugün büyük bir şehirde sokağa çıktığınızda ya da bir toplu ulaşım aracına bindiğinizde yüzleri sanal ekranlara dönmüş onlarca insanla karşılaşmanız tesadüf değildir. Gerçeklik artık içerisinde bulunulan ortamdan uzaklaşmakta ve sanal ortama doğru yol almaktadır. Gerçek ve sanal çizgisinin giderek kaybolmasıyla birlikte bazı değerlerin yitirilmesi ve insani ilişkilerin daha arka planlara atılması kaçınılmazdır.

Bilişim çağının bireylerinde teknolojinin oluşturduğu dijital istilanın etkileri gözlemlenebilir. Teknolojiyle çevrelenmiş bir ortamda insanlar karmaşık düşüncelere sahiptir. Teknolojinin olumsuz etkileri görülmeye başladığı vakit zamanın geri alınamayacağı aşikârdır. Aynı zamanda teknolojinin etkilerden büyük oranda korunmak için toplumun bireylerinin bir mağaraya hapsedilmesi de söz konusu değildir. Ya da teknolojinin oldukça şeytani bir olgu olduğu yönündeki öğütler de çözüm değildir. Zaten teknolojinin sihirli yönleri, vaatleri, teknolojiyle ilgili çözümlemelerin önüne geçmektedir. Teknoloji bağımlılığının tam anlamıla açıklanması hususunda insan-makine etkileşimlerini konu alan çalışmaların artması gerekmektedir. Modern dünyanin en önemli problemlerinden biri olarak değerlendirilen bu konuya ait farklı disiplinlerden çalışmaların ortak bir paydada birleştirilmesi oldukça önemlidir. Zira akside halde Albert Einstein'ın modern teknolojilerle ilgili düşüncelerinden biri olan ve "bir zamandan sonra teknolojinin insan etkileşimini aşacağına" dair endişelerinin ortaya çıkması kaçınılmazdır (Einstein, 2008).

Teknoloji bağımlılığı semptomlarının incelendiği bu çalışma bir kültürel uyanış çağrısını temel almaktadır. Sadece teknoloji karşıtı görüşlere odaklanmaktan ziyade teknoloji bağımlılığına yol açabilecek durumların ortaya koyulması ve birey, kültür, toplum gibi nice farklı boyutlarda hangi semptomlarla ortaya çıkabileceğine yönelik bir incelemedir.

\section{Teknolojik Doz Aşımının Belirlenmesi}

Teknolojinin katkısıyla artık neredeyse her şeyi bilme, öğrenme ya da izleme yeteneği mümkün hale geldi. Aynı zamanda insanlar yerine düşünebilen, izleyen, öğrenen makinaların giderek yaygınlaşmasıyla farklı bir düzen yaratılmış oldu. Sabit disklerin ötesinde bilgi, önceleri sınırları çizilen kapasitelerin çok daha ötesine geçerek yeni görevler üstlendi. Tüm bu gelişmelerin ışı̆̆ında insanlar her gün yüzlerce e-postaya, metinlere ya da teknolojik araçlara bağlanmış vaziyette kendisi için neyin en önemli olduğunu unutmaya başladı. Dikkat dağıtıcı ve bazı çağrıları içerisinde barındıran teknolojiler insanları yönlendirme yoluna gitti. Birçok kişi, kişisel ekranlarına bakmakla meşgulken yapılması gereken işler, kurulması gereken iletişimler kesintiye uğradı. Teknolojinin kolayca ulaşılabilir, taşınabilir olması nedeniyle her yerde insanın bir uzvuymuş gibi bir hale gelen 
teknolojilerle birlikte insanlar teknolojik araçlarını (akıllı telefonları) yatak odalarına, tuvaletlere, duşlara, hatta cenaze törenlerine kadar sokmaya başladı. Bir başka deyişle teknolojik doz aşımı söz konusu hale geldi.

Teknolojilerin hayatı kolaylaştırma vaatlerinin bir karşılığı olarak talep ettiği pasif kullanıcılar olma durumu cihazlara karşı olan farkındalık ve dikkatli olma durumlarını perdelemektedir. Teknolojik doz aşımı, pasif kullanıcı olma durumunun dışında cihazlarını sürekli kontrol etme zorunluluğunu içgüdüsel olarak hisseden, güçlü ruhsal bir durumu olup daha önce herhangi bir şeye bağımlı olmamış insanları bile oldukça değişik şekilde tuzağının içerisine çekmektedir. Son yıllarda yapılan birçok araştırma gösteriyor ki insanlar uykudan daha çok ve ortalama sekiz saatten fazla olmak üzere telefon, bilgisayar ya da video oyun konsollarında zaman geçirmektedir (Yeşilay, 2012). Bu süre giderek artiyor çünkü daha bebeklik dönemlerinden itibaren insanlar teknolojiyle tanışmaya ve iç içe geçmeye başliyor.

Genel anlamda bakıldığında insanlar, hayatın hız kazandığına yönelik ortak bir görüş bildirir. Birçok kişi artan teknoloji kullanımı konusunda endişelerini dile getiriyor. Ve bu durum gözlemlendiğinde tipik olarak iki farklı konuma yerleşen insanların var olduğu görülüyor. Bunlardan ilki teknolojinin her şeyi mahvettiğini düşünen insanlardır. Bugün genç bireyler gerçek yaşamdaki insanlarla nasıl etkileşim kurulacağı yönünde tam olarak bilgi sahibi değil. Çünkü ekranlara bakmaktan öte hiçbir şey umurlarında değil. Yetişkinler bile bir oyalama aracı olarak gördükleri teknoloji nedeniyle birbirleriyle olan gerçek iletişim ikinci plana atıyor. Bu durum toplumun geleceği için kötü emareler içeriyor. İkinci tip konuma yerleşen insanlar ise teknolojiyi bütünüyle kabul eden bir başka ifadeyle teknolojiyi harika olarak değerlendirenlerdir. Teknolojinin hayatın her alanına olumlu etkiler yaptığ1 inkâr edilemez bir gerçek özellikle bundan beş yıl öncesini düşünün o günden bugüne teknoloji anlamında birçok gelişme yaşandı. Ancak ikinci tip konuma yerleşen insanlar genellikle olumsuz gelişmeleri görmezden geliyor. Aslında bakılırsa teknolojik doz aşımı da bu iki uç arasında bir yerlerde konumlanıyor. Teknolojinin hayatı iyileştirip aynı zamanda yeni olumsuzlukları beraberinde getirmesi oldukça ironik.

Bugünün teknolojileri dikkatleri orijinal odağından farklı bir yöne doğru çeken etkileşimleri içermektedir. $\mathrm{Bu}$ nedenle teknolojik araçların çekiciliğinden kurtulmak oldukça zordur. Özellikle video oyunları çok daha kapsamlı bir biçimde insanları kendisine çeker. Günümüzde video oyun piyasasının milyon dolarla ifade edilen satış rakımları bir tesadüf değildir. Dijital cihazlara entegre şekilde yerleşen sanal uygulamalar ve sosyal medya araçları da dikkat dağıtıcı diğer ürünlerdir. Yaşam boyu ekranlarda kalmak yerine hayatı bir jak ve şarj aletinden fazlası olarak görmek gereklidir. Teknolojiyle bütünleşmiş, dozu aşılmış tekno-zihinlerden sıyrılmak bir bakıma zihnin özgürleştirilmesi vücuda yerleşen teknoloji tabanlı zararlı toksinlerden kurtulmaktan geçer. Aksi halde teknolojik araçlar daha akıllı hale geliyor, peki ya biz? soruları cevapsız kalmayı sürdürecek.

Teknoloji bir yandan insanları üretilmiş sanal bir gerçeklikle karşı karşıya getiriyor. Teknoloji dünyasında bireyler, ekranlar aracılığıyla etkileşime geçen ve her şeyi sanallaştıran birer "dijital ajan" gibi davranıyorlar. Hiçbirimiz gerçek dünyaya paralel bir sanal dünyanın üretimine ortak olmaktan kaçamıyoruz; hayatımız, doğal gerçekliğin ötesinde veya doğal 
gerçeklikle bağı çok zayıf olan bir dünyada devam ediyor. Gerçek ve sanal arasındaki çizginin bulanıklaştığ ${ }_{1}$ bu yeniçağda, zaman ve mekân gibi temel epistemolojik kategoriler, geleneksel önemlerini yitirmiş görünüyor fakat öçlerini, bireyleri zamansız kılarak ve yurtsuzlaştırarak alıyorlar. Artırılmış gerçeklik, zenginleştirilmiş içerik, dijitalleşmiş veriler, simüle edilmiş gerçeklikler, modellenmiş davranışlar ve robotikler varlık görüşlerinin ötesini oluşturuyor. Yeni ontolojik yorumlara hatta kuramlara duyulan ihtiyaç, bugün had safhada (Işıklı \& Küçükvardar, 2016, s. 7-8). Geleceği tasarlamaya çalışan araştırmacılar da bedensiz kimlikler yer aldığı simülasyon sistemleri ve makineye dayanan ölümsüzlüğün sembolü olan yapay zekâ çalışmalarıyla günümüz kullanıcıların tercih ettiği araçların alt yapısını oluşturup anlamlandırmaya çalışıyor.

Teknolojik doz aşımıyla birlikte bireylerin bedenleri "şimdi burada" fakat bedenleriyle zihinleri aynı yer değil. Bütünsel bir beden devinimin jest mimikleri yerlerini, yalnızca dokunarak emolojiler yaratan kısıtlı parmak hareketlerine bırakıyor. İnsanların kendilerini kuşatan dünyanın acı, pis ve katlanılmaz gerçeklerinden bir süreliğine uzaklaşmak için artık dağ başına, çöle, mağaralara veya denize gitmeleri gerekmiyor. Gerçek dünyadan bir süreliğine kaçabilme rüyası, "anında çevrimiçi olma" alt yapısı tarafından düşük ücretli bir hizmet olarak bilişim kullanıcılarına sunuluyor. Çevrimiçindeki kişiler, nesneler ve dillerin bu dünyadakinden farklı olması, sanal dünyanın cazibesini oluşturuyor (Işıklı \& Küçükvardar, 2016, s. 227). Teknolojinin aşırı ya da problemli kullanımının sonuçlarını kestirebilmek için bu konuya verilen ağırlığın arttırılması gerekli.

\section{Teknoloji Bağımlılığı Sorunsalının Çözümlenmesi}

Özünde teknolojiye bağlı fakat bağımlı mıyız? Teknoloji bağımlılı̆̆ı kavramı, teknoloji tabanlı olarak ortaya çıkabilen davranış bozukluklarını ifade eder. Her ne kadar kesin olarak kabul edilmiş ve diğer tüm alt bağımlılıkları (bilgisayar bağımlılığı, oyun bağımlılığı, internet bağımlılığı) da içine alacak şekilde geniş bir tanımı bulunmasa da belirli rahatsızlıkları tetikleyip ya da ortaya çıkarabilme potansiyeli bakımından ciddi bir sorun olarak görülür. Teknolojiye yönelik bağımlılık konusu aslına bakılırsa klasik bağımlılık durumlarından farklıdır. Bağımlılıkta insanlar uyuşturucu maddelerine bağımlılık gösterir ancak teknolojide ise direk madde/nesneye bağlılıktan yani bir başka ifadeyle bilgisayara, akıllı telefona, video konsollarına ya da tabletlere direk olarak bağımlılıktan ziyade bu teknolojilerin sunduğu bilgi, eğlence ve kişisel bağlantılara yönelik bir bağımlılık söz konusudur. Örneğin, uyuşturucu bağımlılığında en etkin maddeler hizlı enjekte edilebilenlerdir. Teorik anlamda düşünüldüğünde teknolojiyle sürekli bir hız yarışı söz konusudur ve insanlar bütün işlemlerin saniyeler içerisinde gerçekleşmesini talep eder. $\mathrm{Bu}$ nedenle en hızlı bilgisayarlar, hızlı çalışan akıllı telefonlar ya da daha güçlü video oyun konsolları daha çok talep edilir. Bu durumda teknoloji bağımlılığında klasik bağımlılıkta olduğu gibi bir hız olguyla kesiştiği görülebilir.

Teknoloji bağımlılığı çalışmaları ve araştırmalarına yönelik ciddi tartışmalar mevcuttur. Özellikle teknoloji bağımlılığı konusu üzerine akla gelebilecek ilk sorulardan biri herhangi bir maddenin (uyuşturucunun) ortada bulunmadığı bir durumda nasıl bağımlılık durumu mevcut olabilir. Örneğin, her gün egzersiz yapan biri bağımlı mıdır? Bu ve benzer sorular 
üzerindeki tartışmalar davranışsal bağımlılık konusuyla açıklanabilir. Teknoloji bağımlılığı konusunda çözümlemeler eylemler ve ilgili ihtiyaçların şiddetiyle ilintilidir. Bir teknolojik aracı ya da teknolojinin sunduğu sanal bir ortamı kullanmadan duramayan bir bireyin teknolojik bağımlı semptomları gösterdiğine yönelik ciddi bulgular olabilir. Bugün özellikle akıllı telefonlar üzerinden bu durum kolayca gözlemlenebilir. Bireyler artık akıllı telefonlarından birkaç dakika bile olsa uzak durma konusunda güçlük çekmektedir. Zira toplu taşıma araçlarıyla yapılan bir yolculukta bile kolayca gözlemlenebileceği üzere teknolojinin sunduğu sanal ekranlar/ortamlar büyük bir kesimi etkisi altına aldı.

Teknoloji bağımlılığına yönelik güçlü belirtiler anksiyete, uykusuzluk, depresyon gibi sorunlarla birlikte ortaya çıkmaktadır. Özellikle başkalarıyla iletişim kurmakta zorlanan insanlar, sosyal ilişkilerden uzaklaşmanın kolay bir yolu olarak teknolojiyi görmektedir. Çevrimiçi ilişkilerin gerçek yaşamın önüne geçmesiyle birlikte bireyler teknolojik bağımlılığa yaklaşma yolunda yatkınlık gösterir. Çünkü sosyal ihtiyaçların karşılanması git gidide sanal alan doğru kayan bir çizgide ilerler. Gündelik yaşamda yüksek düzeyde stres yaşayan insanlar bu durumla başa çıabilmek ve varolan sorunlardan uzaklaşmak için de teknolojiye başvurabilir. Buna benzer birçok durum bireylerin teknoloji bağımlısı olması yolunda önemli adımları içerir.

2004'den bu yana ABD'de toplumsal sorunlar ve kamuoyu üzerine araştırmalarını yürüten Pew Araştırma Merkezi'nin 2018 yılı içerisinde gençlerin sosyal medya kullanımı alışkanlıkları üzerine yaptığı bir çalışmada ciddi sonuçlara ulaşıldı. Bugün ABD'de 13-17 yaş arası gençlerin yüzde 51'i Facebook, Youtube, Instagram ya da Snapchat gibi sosyal medya tabanlı uygulamaların en az birini kullanmaktadır. Ve bu yaş aralığındaki gençlerin yüzde 95'i akıllı telefona sahiptir (Pew Research Center, 2018). Teknolojik araç ve sanal uygulamaların kullanımı dünya çapında giderek kullanım alanını arttırmaktadır. Bu nedenle teknoloji bağımlılığı araştırmaları her geçen gün yeni etki ve araştırma alanları kazanıyor.

\section{Teknoloji Bağımlılığı Çalışmalarının Karşılaştırılması}

Teknoloji bağımlılığı kimyasal maddeye dayanmayan davranış bozukluklarını içerir. K. Young'un 1996 yılında ilk adımını attığı internet ve teknoloji bağımlılığı çalışmaları günümüze kadar popüler araştırmaların konusu olmayı sürdürmektedir. Özellikle Amerikan Psikiyatri Birliği'nin Ruhsal Bozuklukların Tanısal El Kitabi (DSM-5) olarak isimlendirdiği çalışmasının üçüncü bölümünde "Internet Oyun Bozuklukları" başlıklı teknolojik rahatsızlıklara değinilmiştir. Buna göre, son 1 yıl içinde günlük hayatı aksatacak ve olumsuz yönde etkileyecek biçimde oyun oynanmasının inceleme altına alınması ve ciddi bulgulara ulaşılması durumunda DSM-5' in gelecek güncellemelerinde bu rahatsızlığın resmi olarak tanınacağına yönelik tavsiye kararı verilmiştir. Aynı zamanda tavsiye kararları içerisinde teknolojik bağımlılığa yol açabilecek 9 semptomdan bahsedilmektedir (American Psychiatric Association, 2013).

2013 yılında DSM-5'in teknoloji tabanlı bağımlılığa yönelik tavsiye kararlarının ardından ilerleyen yıllarda birçok çalışma yapıldı. Özellikle Dünya Sağlık Örgütü (WHO), Haziran 2018'de Uluslararası Hastalıkları Sinıflandırdığı (ICD-11) 'de "Oyun Bağımlılı̆̆ını" bir ruhsal sağlık problemi olarak resmen tanıdı. WHO'ya göre, dünya çağındaki problemlerin 
çözüme kavuştuğu bu sınıflandırma çalışmalarında teknoloji tabanlı bir bağımlılık ilk kez ciddi şekilde geniş çaplı ele alındı. Aynı zamanda oyun bağımlılığının tanısı, tedavisi ve sürekli tekrar etme, davranışları etkileme açısından ciddi problemler oluşturabileceğine yönelik çözümlemelere yer verildi. Amerikan Psikiyatri Birliğinin internet bağımlılığı için verdiği ve WHO'nun ilk defa tanıdığı oyun bağımlılığı semptomlarının karşılaştırması konunun daha iyi çözümlenmesine yardımcı olacaktır (Tablo-1):

\section{DSM-5 Internet Bağımlılığı Semptomları}

Zihinsel Meşguliyet

Geri Çekilme Belirtileri

Giderek Artan Zaman

Kontrol Yitimi ve Başarısız Denemeler

Olumsuz Durumlara Rağmen Devam Edl.

Aktivitelerden Feragat

Kaçınma Durumları

Uyar1 Durumları

\section{Önemli Süreçlerin İkinci Plana Atılması}

Tablo-1: Internet Bağımlılığı ve Oyun Bağımlılığ Semptomlarının Karşılaştırılması

DSM-5'de internet bağımlılı̆̆ı semptomlarına ait 9 temel kriter bulunmaktadır. Bunlardan ilki zihinsel meşguliyet olgusuyla insanların teknolojik araçları düşünme, düşleme ve sürekli teknolojik araçlarla olma isteğine yapılan vurguyu ifade eder. İkinci semptom ise geri çekilme belirtileri olan teknolojik araçları kullanmayı bırakan bireylerde görülen sinirlilik, ruh hali değişikleri ya da üzüntü gibi durumları ifade eder. Üçüncü semptom teknolojik araçların giderek artan kullanım ve önüne geçilemeyen zaman aralıklarını ifade eder. Dördüncü semptom teknoloji üzerindeki kontrolün yitimi ve teknolojiyi bırakma yönünde istekli olunmasına karşın başarısız denemeleri içermektedir. Beşinci semptom ise teknolojik araçların kullanılması sürecinde bazı psikolojik tabanlı olumsuz durumların ortaya çıkması ve buna rağmen kullanılmasının devam edilmesi gibi durumları içerir. Altıncı semptom, bireyin daha önce yaptığı çeşitli aktiviteler, hobiler vd. davranışların terki bunların yerini teknoloji kullanımının alması süreçlerini içerir. Yedinci semptom, gerçek yaşamda ortaya çıkan olumsuz durumlardan bir kaçış aracı olarak teknolojinin görülmesi ve ona başvurulmasını içerir. Sekizinci semptom, bireyin aile üyeleri ya da hayatında önemli gördüğü kişiler tarafından teknoloji kullanımı yüzünden uyarılması ancak bu durumlara aldırış etmemesini ifade eder. Dokuzuncu semptom ise bireyin teknolojik araçları kullanma uğruna hayatında yer alan önemli iş, ilişki, bağlantı ya da çeşitli süreçleri ötelemesi, ikinci plana atması süreçlerini içerir.

WHO'nun resmen tanıdığı oyun bağımlılığı semptomlarından birincisi bireylerin dijital olarak tercih ettiği oyunları hangi aşamada, ne sıklıkla tercih ettiğinin belirlenmesine yöneliktir. İkinci semptom, bireylerin oynadı̆̆ı oyunların yoğunluğunun ne şekilde 
olduğunu ifade eder. Üçüncü semptom ise bireylerin oyunları ne kadar süreyle oynadığı, günlük oyun oynama sürelerini ifade eder. Dördüncü semptom, oyun bağımlısı olabilecek düzeydeki bireylerin tercih ettiği aktivitelerin belirlenmesi üzerinedir. Beşinci ve son semptom ise bireyin oyun oynamaktan kaynaklı olarak ortaya çıan olumsuz durumlarla ne şekilde baş edebildiği bu olumsuz durumlara rağmen hala oyun oynamaya devam edip etmediğinin tespit edilmesi üzerine odaklanmaktadır.

Tavsiye edilen ve resmi olarak tanınan teknolojik kaynaklı semptomların ortak noktasına bakıldığında teknolojik araçların ne kadar süreyle kullandığı, yoğunluğu, sıklığı, olumsuz durumlar oluşturup oluşturmadığı eğer oluşturuyorsa kullanıcının buna hala devam edip etmediği, hayatında tercih ettiği aktivitelerin teknoloji kullanımı öncesi ve sonrası değişip değişmediği gibi ortak semptomların olduğu görülmektedir. Ayrıca WHO teknolojiyle bağlantılı sıkıntılı durumların görüldüğü vakalarda, bireylerin kesin olarak oyun bağımlısı sayılabilmesi için minimum 12 ay gibi bir sürenin geçmesi ve bireyin bu süre zarfında ilgili semptomları göstermesi gerektiğini vurgular.

\section{Dijital Hastalık Belirtilerinin Değerlendirilmesi}

Bilişim devriminin ayrılmaz parçası olan sanal ortamın dönüşümü sonucu modern hayatın her yerine nüfuz eden siber ağlar insanlığın ayrılmaz birer parçası haline geldi. İnsanlar artık doğrudan teknoloji kullanımına bağlı olarak görülen farklı zihinsel rahatsızlıkların sayısının artışına tanık olmaktadır. Çok yakın zamana kadar farklı bilimsel alanlarda yok sayılan bu hastalıklar artık çeşitli olgular altında açıklanmakta, sayıları hızla artmakta ve bilimsel araştırmaların konusu haline gelmektedirler. Teknoloji günlük hayata nufüz eden kritik bir zorunluluk gibi görünüyor. İnsanlar akıllı telefonları veya internetleri olmadan bir yere gitmek nasıl bir şey olur diye düşünememektedir. Bununla birlikte dijital hastalık belirtileri özellikle çocuklar ve gençler arasında keskin bir artış göstermektedir. Teknolojiden uzak durmak oldukça zor olmasına rağmen ondan yine de mümkündür. Uzak durmak özgürlük alanıyla bağlantılıdır. Özgürlük alanı, üretilen teknolojik cihazların bileklere geçirilmiş birer kelepçe olmadığı fark edildiği an anlam kazanır. Fark etmek ve olayların bilincine varmak için dijital hastalık belirtileri hakkında fikir sahibi olmak oldukça önemlidir.

Teknolojinin yarattığı hızlı bilgi akışı ve olayların ışık hızında iletişim kanallarıyla yayılması, bireylerde olup bitenleri sürekli takip etme isteği uyandırmaktadır. Özellikle yaşananları takip edemeyen bireylerde "Olup bitenlerden yoksunluk" (Fear of missing out- FOMO) olarak tanımlanan çeşitli olumsuz durumlar ortaya çıkmaktadır. Teknoloji bağımlılığının belirtilerini taşıyan birey sosyal alanın içeriğine ulaşamaz ya da ona sanal anlamda dokunamaz ise FOMO durumu tetiklenebilir. Teknolojinin gelişimiyle birlikte insanların sosyal ilişkileri sanal alanlara doğru kaymıştır. Cep telefonları, akıllı tabletler gibi modern teknolojilerin sosyal ağlarla ilişkisi bir süre sonra boyut değiştirmekte ve artan bir bağımlılığa dönüşmektedir. Yapılan araştırmalar, bağımlılığın yani çevrimiçi iletişim ya da teknolojiyle olan hattın kesilmesi durumunda bireyde eksik kalma korkusu, anksiyete bozuklukları hatta patolojik durumlar görülebileceğini ortaya koymaktadır (Song, Larose, Eastin, \& Lin, 2004, s. 384-394). Teknoloji bağımlılığının semptomlarından biri olan gergin ve kaygılı olma durumu, FOMO'da kendini gösterir. Her gün içerisinde olduğu ve sürekli takip 
ettiği gündemden uzak kalan birey için endişe durumu ortaya çıkabilir. Bu durumda kişi bunu ortadan kaldıracak girişimlerde bulunur ve eskiye dönüş yolu arar.

Teknolojinin dönüşümü ve popülaritesine katkı sağlayan en önemli araçların başında kuşkusuz cep telefonları gelmektedir. Akıllı telefonların yarattığı dönüşüm ve kullanım yoğunluğu bazı sorunları da beraberinde getirmiştir. Telefonlarını kaybetme, onları kullanamama korkusu olarak adlandırılan "Nomofobi" (Nomophobia), kavramı teknoloji ve sanal ilişkisinin yarattı̆̆ 1 problemlerdendir. İngilizce "no mobile phobia" kelimesinden türetilmiştir. Genellikle düşük benlik saygısı ve kendine güven eksikliği gibi psikolojik faktörler bu davranışın temelini oluşturmaktadır. Araştırmalara göre, ilgili kişilerin sosyal fobi, sosyal kaygı bozukluğu ve / veya panik bozukluğundan muzdarip olma olasılığ yüksektir.

Anna King, Alexandre Valença ve arkadaşlarının 2014'de nomofobi üzerine yaptı̆̆ bir araştırmada, cep telefonunun aşırı kullanımının çeşitli psikolojik faktörleri etkilediği ortaya konulmuştur. Bunlar özellikle de cep telefonunu uygun olmayan yollarla kullandıklarında ortaya çıkan; düşük öz saygı ve bağımlılık semptomlarıdır. Ayrıca nomofobik semptomların altında yatan nedenler ve önceden var olan zihinsel rahatsızlıklar, sosyal fobi ya da sosyal anksiyete bozukluğu dâhil muhtemel psikolojik bozukluklar ile panik bozukluklar arasındaki konulara yönelik ilişkiler ortaya konulmuştur (King, Valenca, \& Silva, 2013, s. 140-144). James Roberts, Chris Manolis ve arkadaşlarının 2014 yılında "Görünmez bağımlılık: Cep telefonu bağımlılığı" ismiyle kaleme aldıkları bir başka nomofobi araştırmasında konuyla ilgili dikkat çekici sonuçlara ulaşılmıştır. Araştırmaya göre gençlerin ve ergenlerin nomofobi davranışlar sergilemeye daha yatkın oldukları, cep telefonu ve teknolojiye ulaşamadıklarında kaygılı davranışlar sergiledikleri ve negatif bakış, içe kapanma, teknolojiyi arama hissi gibi davranışlar ortaya koydukları ifade edilmiştir (Roberts, Petnj1, \& Manolis, 2014, s. 254-265). Diğer nomofobi araştırmalardan hareketle teknoloji kullanımının 21.yüzyılın en büyük uyuşturucu içermeyen bağımlılık belirtilerinden biri olduğu ifade edilebilir.

Tekno-stres (Techno-stress), insan-teknoloji ilişkisi sonucu ortaya çıkan olumsuz psikolojik durumları içeren bir kavramdır. İnsanlar ve makinelerin fiziksel birlikteliği ev ve ofislerdeki modern bilişim teknolojilerin varlığı gibi durumlar hem gündelik ilişki hem de iş süreçlerindeki alışkanlıkları değiştirmiştir. Gündelik yaşam ve iş süreçlerindeki bu değişiklere tam olarak adapte olamayan ve bununla başa çıkamayan bireylerde tekno-stres görülebilir. Bilişim teknolojilerinin yarattı̆̆ hız olgusu nedeniyle sürekli bir tempo içerisinde olan günümüz bireyi iş ve ilişkilerinde belirli zorlayıcılarla karşılaşır ve bunlara zamanında hızlı bir şekilde yanıt verme zorunluluğu hissetmektedir.

TS kavramını ilk ortaya atan ve bu kavramla ismi bütünleşen araştırmacı Craig Brod'a göre, yeni bilişim teknolojileriyle sağlıklı bir şekilde mücadele edilememesi sonucu ortaya çıkan bu durum modern adaptasyon hastalığını işaret etmektedir. C.Brod, tekno-stresin bilgisayar, tablet, akıllı telefonlar başta olmak üzere iletişim temelli cihazların kullanılmasıyla ortaya çıan ve istenmeyen bir durum olduğunu ileri sürer. Aynı zamanda cinsiyet, yaş, bilişim araçları kullanım durumu gibi değişkenlere göre tekno-stres farklılık gösterebilir. C.Brod'a 
göre, kadınlar erkeklerden daha düşük tekno-stres yaşarlar, yaşlı insanlar ise genç insanlara göre daha az. Daha çok bilgisayar okuryazarlığı olanlar ise daha düşük tekno-stres deneyimi yaşarlar (Brod, 1984).

TS durumunun oluşması genellikle belirli durumların karşılanmadığı ya da bilgi eksikliğinin yarattı̆̆ı olumsuz koşullar altında ortaya çıkar:

Teknolojik değişimin hızlı olması nedeniyle zamanın da hızlanması,

Değişen düzen ve hızlı koşullara uygun yeterli eğitimin olmaması,

Yoğun iş yükü,

Teknolojiler konusunda tutarlı bir düzenin olmaması, anlam karışıklıkları,

Donanım ve yazılım konusunda eksiklik, güvenilirliğin tam olarak sağlanamaması.

$\mathrm{Bu}$ ve bunun gibi çeşitli teknoloji tabanlı sıkıntılar TS'nin oluşumuna katkı sağlar. 21. yüzyılda insanlar kendilerine daha iyi bir yaşam sunulması için teknolojiyle donatılmıştır. Ancak gerek gündelik yaşamda gerekse iş süreçlerinde bireyler ekranlara, bilgisayar monitörlerine daha uzun süre bakmak zorunda kaliyor ve bunun sonucunda hem fiziksel hem de ruhsal sorunlarla karşılaşıyor. Bilişim alanında çalışan ve en az sekiz saatini bilişim araçlarıyla harcamak zorunda kalan bir birey düşünüldüğünde TS'in ne denli fiziksel olarak ortaya çıkabileceği az çok kestirebilir. Fiziksel olarak boyun, sırt, bel ağrısı, gözlerde yorulma gibi fiziksel etkilerin ortaya çıkabileceği TS'de ayrıca duygusal olarak da bunalım, çöküntü, isteksizlik gibi durumların da görülebileceği söylenebilir. Teknolojilerin ve sanal ortamların günden güne çeşitlenmesi daha farklı dijital hastalık belirtilerini gündeme getirecektir.

\section{SONUÇ}

Bağımlılığa yönelik çalışmalar uzun bir süre sadece madde bağımlılı̆̆ı ile ilişkilendirildi. Ancak 1990'lardan itibaren teknoloji konusunda yaşanan gelişmeler, insanların teknoloji kullanım konusunda yaşadığı sorunlu davranışların giderek artmasıyla birlikte uzmanlar, teknoloji bağımlılığı konusuna ciddi boyutta ağırlık verdi. Temel ihtiyaçların bile teknoloji yoluyla ya da teknoloji tabanlı olarak giderilmesine yönelik girişimler, gençlerin yaşadığı stresten bir kaçış aracı olarak gördükleri teknolojiler modern çalışmaların temel araştırma konusu oldu. Dünya artık insanların parmak uçlarının altında fakat teknoloji konusunda nelerin olduğu ya da etkilerinin hangi aşamada olduğuna yönelik arayışlar hiç bu kadar zorlayıcı olmadı. Bugün yapılan çalışmalar, teknolojiye yönelik çözümlemeler incelendiğinde teknolojiyi çok kullanmanız, video izlemeniz veyahut internetten alışveriş yapmanız sizin teknoloji bağımlısı olduğunu kesin olarak göstermiyor. Ancak teknoloji tabanlı olarak yaptığınız bu eylemlerin gerçek yaşamdaki hayatınızın önüne geçtiği durumlarda problem başlıyor.

Her geçen gün sayısız teknolojik ürünün piyasaya sürüldüğü, milyonlarca dolar para kazandıran dijital oyunların yaygınlığını arttırdığı ve sanal uygulamaların insanın temel ihtiyaçlarından biri haline geldiği günümüzde, adeta makineleşen ilişki ve davranışların 
çözümlenmesi teknolojiyle mücadeleden geçer. Mücadele yapay ihtiyaçların oluşturulduğu ve muhtemelen gelecek yıllarda insanlığı teslim altına alacak olan bir düzlemde devam edecek. Teknolojinin insan hayatını ne yöne doğru götüreceği ve teknoloji bağımlılığının dünyaya hangi boyutta yayılacağı yine insani yapıyla bağlantılı. İki yanı keskin bir bıçak olarak değerlendirebileceğimiz teknolojiler ya insana hizmet edecek ya da mücadeleden vazgeçildiği anda insanın teknolojiye yönelik köleliği perçinlenecektir. Teknoloji hayatlarımızda önemli değişimler yarattı ancak hayatın bir alternatifi olarak görülmemeli. Hoşgörü, sabır, empati ve hayal kırıklıkları ve daha birçok insani değerler teknolojiden bağımsız yaşanılarak öğrenilmeli. İnsanlarla ve toplumla etkileşimlerden kaçınmak, bunlarla baş etmemek için yollar aramak ya da bulmak kaçınılmaz olanı sadece geciktirecektir.

Teknoloji bağımlılığının kesin sınırlarla açıklanması hususunda farklı bakış açıları ve metotları içeren çalışmalara ihtiyaç var. Konunun oldukça farklı ve geniş alanları barındırması, onu ileriye taşıyacak çok boyutlu alan araştırmalarını gerekli kılmaktadır. Modern dünyanın sendromu olan bu olguya yönelik yavaş yavaş hipotezler çeşitlendirilmekte ve ortak bir sonuç paydasında birleşilmeye çalışılmaktadır. Bu çalışma özü itibariyle teknoloji bağımlılı̆̆ına yönelik semptomları incelemekte ve karşılaştırmaktadır. Bir anti-teknoloji bakışı açısından ziyade teknoloji bağımlılı̆̆ı olgusunun hangi durumlarda görülebileceğine yönelik belirtileri tasvir etmektedir. Dolayısıyla bir kültürel uyanış çağrısı olarak değerlendirilebilir. Ayrıca olumsuz etkileri anlamaya yardımcı olabilecek literatür tabanlı bir incelemedir. Teknoloji bağımlılığı çözümlemelerinin kesin bir sonuca ulaştırılması uzun bir süreç olacak gibi gözüküyor. Hem toplumsal değişimlerin anlaşılması hem de teknoloji tabanlı dinamikleri düşünce becerileri çerçevesinden tahlil edilmesi oldukça karmaşık bir süreç. Üstelik kültürel yapının her yeni kuşakta daha çok değişikliğe uğraması da ayrı bir problem. Dijital çağın sahip olduğu dönüştürme gücünün güçlü ve sosyal bir değişimle birleştiği günümüzde teknoloji bağımlılığına yönelik ortaya atılan çeşitli teorilerin araştırmalarla desteklenmesi ve dijital çağında ötesine giden toplumun daha ayrıntılı tasvir edilmesi konu üzerine odaklanan araştırmacıların işini kolaylaştıracaktır.

\section{KAYNAKÇA}

American Psychiatric Association. (2013). Diagnostic and Statistical Manual of Mental Disorders (DSM-5). Arlington: Apa publishing.

Brod, C. (1984). Technostress: The Human Cost Of The Computer Revolution. Michigan: Addison Wesley publishing.

Einstein, A. (2008). Benim Gözümden Dünya (12 b.). İstanbul: Alfa yayıncllık.

Işıklı, Ş., \& Küçükvardar, M. (2016). Bilişim Devrimi: Teknolojinin Felsefi ve Sosyolojik Analizi (1 b.). Ankara: Birleşik yayınevi.

King, A., Valenca, A., \& Silva, A. (2013). Nomophobia: Dependency On Virtual Environments Or Social Phobia? Computers in Human Behavior, 140-144.

Pew Research Center. (2018, 5 31). Teens, Social Media \& Technology 2018. Pew Research Center: http://www.pewinternet.org/2018/05/31/teens-social-media-technology-2018/ adresinden alınd 1 
Platon. (2014). Phaidros ya da Güzellik Üzerine. Ankara: Bilgesu yayıncılık.

Roberts, J., Petnj1, L., \& Manolis, C. (2014). The Invisible Addiction: Cell-phone Activities And Addiction Among Male And Female College Students. Journal Of Behavioral Addictions, 254-265.

Song, I., Larose, R., Eastin, M., \& Lin, C. (2004). Internet Gratifications and Internet Addiction: On the Uses and Abuses of New Media. CyberPsychology \& Behavior(7), 384-394.

Yeşilay. (2012). Teknoloji Bağımlılığı Bildirileri, I. Uluslarası Teknoloji Bağımlılığı Kongresi (s. 73). İstanbul: Gülmat matbaacilık. 